\section{Skp2-dependent degradation of p27kip1 is essential for cell cycle progression}

\author{
Uta Kossatz, ${ }^{1,2}$ Nils Dietrich, ${ }^{1,2}$ Lars Zender, ${ }^{1}$ \\ Jan Buer, ${ }^{3}$ Michael P. Manns, ${ }^{1}$ \\ and Nisar P. Malek ${ }^{1,2,4}$ \\ ${ }^{1}$ Department of Gastroenterology, Hepatology \\ and Endocrinology and ${ }^{2}$ Institute for Molecular Biology, \\ Hannover Medical School, Hannover, Germany; ${ }^{3}$ Gesellschaft \\ für Biotechnologische Forschung, Braunschweig, Germany
}

The activity of the $\mathrm{SCF}^{\text {skp2 }} \mathrm{E} 3$ ligase is required for the proteolytic turnover of several proteins involved in cell cycle control and transcriptional regulation. Loss of skp2 in the mouse leads to a complex phenotype including changes in cell size and DNA content as well as severe proliferation defects. Here we show that the loss of a single skp2 substrate, namely, the cyclin kinase inhibitor p27kip1, reverts the phenotype of skp2 knockout hepatocytes to normal. By comparing the kinetics of $\mathbf{p} 27$ turnover and cell cycle progression in skp2 knockout and p27T187A knock-in mice, we define a short period in G1 in which p27 is able to block the cell cycle after the exit from quiescence. Loss of p27 turnover during this period prevents mitotic division and instead leads to compensatory cell growth.

Supplemental material is available at http://www.genesdev.org.

Received May 5, 2004; revised version accepted September 1, 2004.

The cyclin kinase inhibitor p27kip1 is a central regulator of the cell cycle. Overexpression of p27 arrests cells in G1 (Coats et al. 1996), while loss of p27 leads to an increase in cell proliferation as shown in p27 knockout mice, which develop enlarged organs and are significantly bigger than wild-type mice (Fero et al. 1996; Kiyokawa et al. 1996; Nakayama et al. 1996). In contrast to other tumor-suppressor proteins, the p27 gene is rarely mutated in tumor cells that express low levels of the protein, indicating an important role for posttranscriptional mechanisms in the turnover of p27. The favored model involves the phosphorylation of p27 at a conserved threonine (T187) during late G1, which leads to the multiubiquitylation of $\mathrm{p} 27$ by the skp2-containing Skp-Cullin-F-box (SCF ${ }^{\text {skp2 }}$ ) complex and its subsequent proteasomal degradation (Sheaff et al. 1997; Carrano et al. 1999; Montagnoli et al. 1999; Sutterluty et al. 1999). In this model, the F-box protein skp2 acts as an adaptor, which recognizes phosphorylated p27 and facilitates its ubiquitylation by the $\mathrm{SCF}^{\mathrm{skp} 2}$ complex.

[Keywords: p27kip1; skp2; proteolysis; cell size; proliferation] ${ }^{4}$ Corresponding author.

E-MAIL Malek.Nisar@MH-Hannover.de; FAX 01149-511-532-4283. Article and publication are at http://www.genesdev.org/cgi/doi/10.1101/ $\operatorname{gad} .321004$.
In addition to $\mathrm{p} 27, \mathrm{skp} 2$ has been shown to mediate the ubiquitylation of other cyclin kinase inhibitors like p21, p57, and p130 (Tedesco et al. 2002; Bornstein et al. 2003; Kamura et al. 2003). It is also involved in the transcriptional activation and turnover of the c-Myc oncoprotein (Kim et al. 2003; von der Lehr et al. 2003) and the replication control proteins hORC1 and cdt1 (Mendez et al. 2002; Li et al. 2003). The skp2 knockout mouse displays several phenotypes that confirm the importance of this protein in the control of cell cycle progression. These phenotypes include changes in cell and nuclear sizes, centrosome abnormalities, and proliferation defects $(\mathrm{Na}-$ kayama et al. 2000). Given that cyclin-dependent kinases are involved in the control of all of these processes, we hypothesized that $\mathrm{p} 27$ that accumulates to high levels in the skp2 knockout mouse may contribute to some of the observed changes. Thus, in this study, we examined the phenotype of skp2/p27 double-knockout mice.

We found that the phenotypes described in the skp2 knockout mouse are reverted to normal in the skp2/p27 double-knockout animals. Furthermore, by comparing the kinetics of p27 degradation in skp2 knockout and p27T187A knock-in livers during the course of liver regeneration, we define a short period during early G1 in which p27 is able to induce a cell cycle arrest.

\section{Results and Discussion}

Loss of p27 rescues the cell size and ploidy phenotype in skp2 knockout mice

To directly test the contribution of $\mathrm{p} 27$ to the skp2 knockout phenotype, we created skp2/p27 doubleknockout mice and studied the phenotype of this strain.

The liver of the skp2 knockout mouse is the most severely affected organ, displaying pronounced changes in cell and nuclear sizes as shown in Figure 1A. Therefore, we began our analysis of the skp2/p27 doubleknockout mouse with a size measurement of individual hepatocytes stained with a $\beta$-catenin antibody to allow differentiation of cell borders (Guidotti et al. 2003). Using this technique, we determined that skp2 knockout hepatocytes are on average twice as large as wild-type liver cells (Fig. 1B), which leads to a concomitant reduction of liver cell numbers per visual field (Fig. 1C). The skp2/p27 double-knockout hepatocytes, however, when compared with wild-type hepatocytes did not show any significant enlargement (Fig. 1B), indicating that the increase in liver cell size of the skp2 knockout mouse was normalized by the loss of $\mathrm{p} 27$.

In addition to the significant differences in cell size, we also observed that many of the largest cells displayed the biggest nuclear sizes. This increase had previously been observed in several different cell types in the skp2 knockout mouse, including hepatocytes, renal tubular cells, lung epithelial cells, and sperm cells, and attributed to an increase in DNA content (Nakayama et al. 2000). To test whether the loss of p27 in the skp2/p27 double knockouts led to a reduction in the amount of nuclear DNA, we measured the DNA content of individual hepatocytes in Feulgen-stained liver sections. As shown in Figure 2A, skp2 knockout hepatocytes compared with wild-type hepatocytes show extreme polyploidy with DNA contents up to $16 \mathrm{n}$. This phenotype 
A

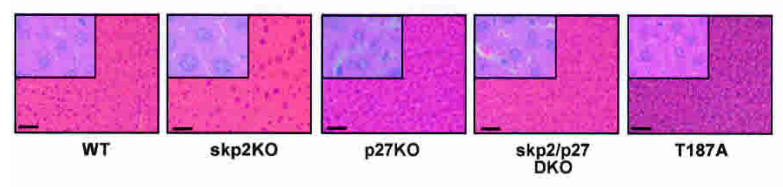

B
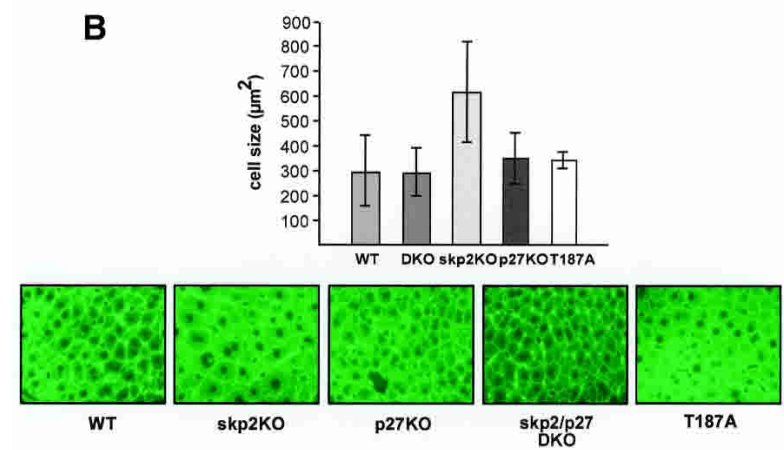

C

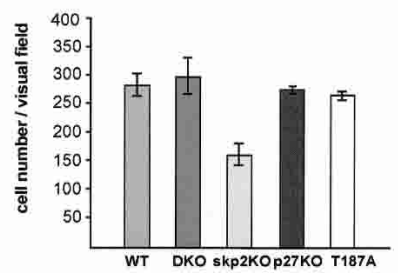

Figure 1. Loss of p27 rescues the cell size phenotype observed in skp2 knockout hepatocytes. (A) H\&E-stained liver sections of the indicated mouse strains. Bar, $40 \mu \mathrm{m}$. (B) Analysis of hepatocyte size. Paraffin sections of liver tissue were stained with a $\beta$-catenin antibody to visualize the cell borders (40× magnification). A total of 300 cells per genotype were counted, and the average cell size was determined using the analySIS 3.0 photometric system. (C) Quantification of hepatocyte numbers per visual field after $\beta$-catenin staining.

was partially rescued in the skp2/p27 double-knockout hepatocytes. Although we did not observe significant increases in DNA ploidy higher than 8n, we did observe a persistent difference in the number of $8 \mathrm{n}$ hepatocytes in skp2/p27 double-knockout mice, indicating that in addition to p27, other substrates of skp2 might influence the generation of these nuclei. The difference in nuclear size observed in skp2 knockout hepatocytes was reverted to normal in the skp2/p27 double-knockout strain (Fig. 2B).

Histological examinations of lung tissue in skp2/p27 double-knockout mice showed a normalization of the previously described changes in cell size between skp2 knockout and wild-type mice (Nakayama et al. 2000), suggesting that the described effects of p27 loss in the skp2 knockout background were not restricted to liver tissue (Supplementary Fig. 1A).

Rescue of the proliferation defects in skp2/p27 double-knockout mice

In addition to the size and ploidy phenotypes caused by the accumulation of p27 in quiescent cells, the loss of skp2 also leads to severe proliferation defects affecting lymphocytes, embryonic fibroblasts, and hepatocytes (Nakayama et al. 2000). The most striking alteration is observed after partial hepatectomy $(\mathrm{PH})$, a procedure in which $70 \%$ of the mouse liver is removed. The reduction in liver mass induces a synchronous re-entry of the remaining hepatocytes into the cell cycle, which leads to the complete regeneration of the organ. A previous study (Minamishima and Nakayama 2002) showed that skp2 knockout hepatocytes will enter the cell cycle after $\mathrm{PH}$, but are unable to exit $\mathrm{S}$ phase and instead undergo multiple endoreduplication cycles. The increase in DNA content is accompanied by an increase in cellular size, allowing the regeneration of the organ by compensatory growth.

Given that loss of p27 rescues the skp2 knockout cell size phenotype in quiescent cells, we speculated that this proliferation defect may also be caused by an accumulation of p27. Thus, we performed partial hepatectomies in skp2 knockout, skp2/p27 double-knockout and wild-type mice and compared the kinetics of cell cycle progression. Whereas skp2 knockout mice incorporate BrdU at significantly reduced levels (Fig. $3 \mathrm{~A}_{\text {; }}$ as previously reported, Minamishima and Nakayama 2002), wild-type and skp2/p27 double-knockout mice showed comparable numbers of BrdU-positive cells between 24 and $60 \mathrm{~h}$ post- $\mathrm{PH}$, indicating normal kinetics of cell cycle entry and progression (Fig. 3A). As skp2 knockout mice are unable to enter mitosis, we verified that pro-
A

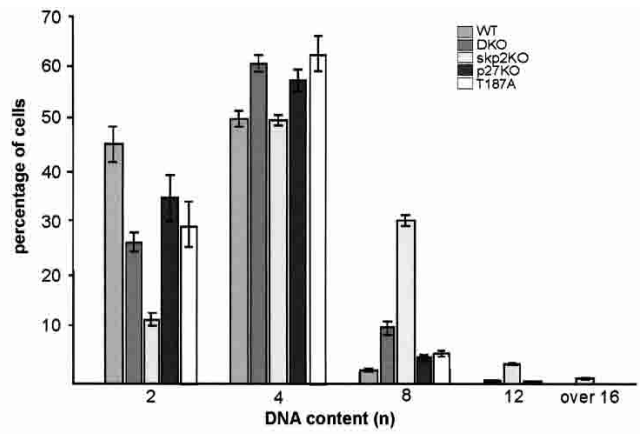

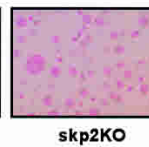
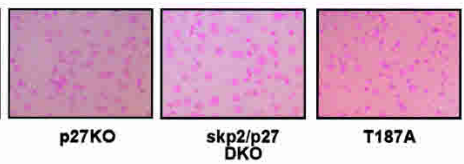

B

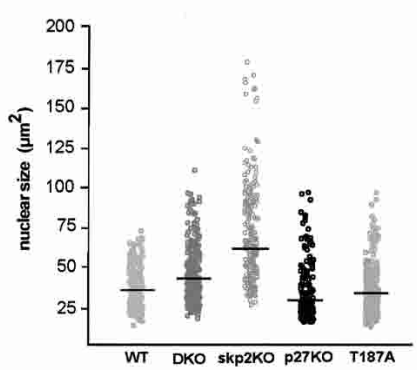

Figure 2. Effect of p27 loss on the ploidy phenotype of skp2 knockout mice. $(A)$ The DNA content of hepatocytes from the indicated mouse strains was determined by microphotometry analysis of Feulgen-stained liver sections. (B) Analysis of nuclear size. A total of 500 nuclei per genotype were analyzed using the analySIS 3.0 photometric system to determine the average nuclear size. Skp2 knockout mice show significantly increased nuclear sizes compared with the other genotypes (p value of difference in nuclear size relative to skp2 knockout: ko:wt 0.0086; ko:dko 0.03; ko:p27ko 0.012; ko:t187a 0.014; dko:wt 0.43). 
A

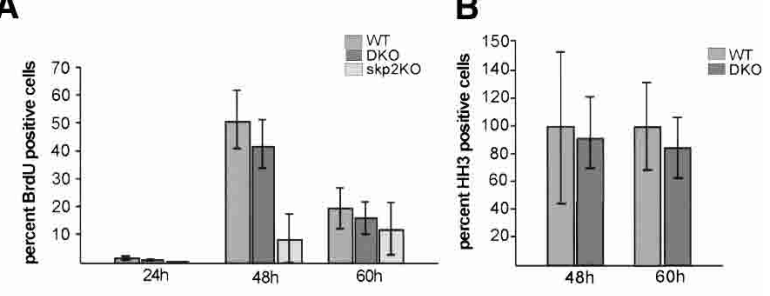

C

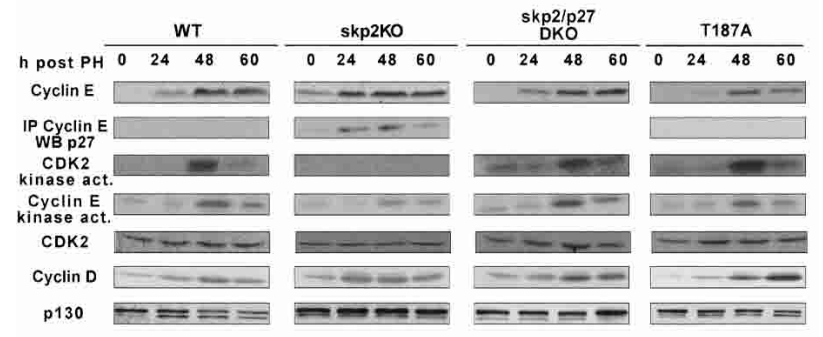

D

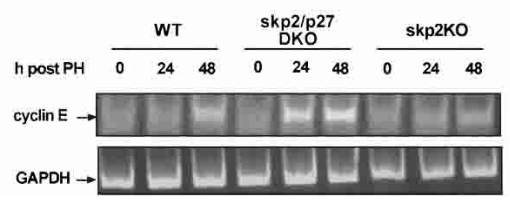

Figure 3. Loss of p27 allows skp2 knockout mice to pass through S phase and mitosis. Quantification of the number of $\operatorname{BrdU}(A)$ and phospho-Histone H3-positive $(B)$ cells after induction of liver regeneration in wild-type, double-knockout, and skp2 knockout mice. For BrdU staining, an average of 900-2000 cells and for HH3 staining at least 500 cells from up to three mice per time point were counted. The average number of HH3-positive cells in the wild-type mouse was set as $100 \%$. The number of HH3-positive cells for skp2/p27 double-knockout mice is displayed relative to the number of $\mathrm{HH}$ positive cells in wild-type mice. (C) Analysis of the expression levels of cyclin E, cdk2, cyclin D1, and p130; detection of cyclin E-associated kinase activity; and determination of the amount of $\mathrm{p} 27$ bound to cyclin $\mathrm{E}$ in whole-cell liver lysates at the indicated time points after induction of liver regeneration in the indicated mouse strains. (D) Semiquantitative RT-PCR of cyclin E cDNA using GAPDH as an internal standard.

gression through the G2 and M phases of the cell cycle was normal in the skp2/p27 double-knockout mice by staining liver tissue at 48 and $60 \mathrm{~h}$ post-PH with a Histone $\mathrm{H} 3$ antibody to visualize passage into mitosis. We detected no differences in the number and intensity of staining between the wild-type and double-knockout animals (Fig. 3B), indicating a complete rescue of the hepatocyte proliferation defect in the skp2 knockout mouse by loss of $\mathrm{p} 27$.

\section{The turnover of cyclin $E$ is coupled} to the degradation of $p 27$

Given that skp2 was shown to be involved in the turnover of several proteins involved in cell cycle control (cyclin E, p130, p21), it was surprising to us that the phenotype of the skp2 knockout mouse was rescued simply by the loss of p27. We therefore asked whether the loss of p27 might have changed the expression levels of other known skp2 substrates. We concentrated our analysis on cyclin $\mathrm{E}$ as it is the most important target for p27-induced cell cycle inhibition and was identified as a potential skp2 substrate because of its accumulation in skp2 knockout cells (Nakayama et al. 2000). As shown in Figure 3C, hepatocytes from skp2 knockout mice contain significantly increased amounts of cyclin E. In contrast, skp2/p27 double-knockout and wild-type hepatocytes express cyclin $\mathrm{E}$ at identical levels in quiescent cells and after the induction of organ regeneration (Fig. 3C; Supplementary Fig. 1B), indicating that the stabilization of p27 in the skp2 knockout cells may have interfered with cyclin $\mathrm{E}$ turnover. The regulation of cyclin $\mathrm{E}$ expression is not solely dependent on posttranslational mechanisms but is also controlled at the transcriptional level (Ohtani et al. 1995). Therefore, we first showed that cyclin D1 is expressed in skp2 knockout hepatocytes (Fig. 3C), indicating that the mitogen-dependent induction of cyclin D expression is not altered by the loss of skp2. In line with this observation we found that the levels of cyclin E mRNA, the essential cyclin D target (Geng et al. 1999), were not significantly changed in skp2 knockout mice compared with wild-type mice as measured by semiquantitative RT-PCR (Fig. 3D). We did, however, observe an earlier and stronger induction of cyclin E mRNA expression in the skp2/p27 doubleknockout mouse after PH (Fig. 3D). This increase in transcription did not lead to differences in cyclin E protein expression compared with wild-type mice, indicating that cyclin E protein levels are tightly controlled by posttranscriptional mechanisms, which do not rely on the expression of skp2. As shown in Figure 3C, cyclin E forms complexes with p27 in skp2 knockout cells in the absence of detectable cdk2 kinase activity and with only residual cyclin E-associated kinase activity remaining. This difference in detectable kinase activity is most likely caused by the varying abilities of the different antibodies to immunoprecipitate active cyclin kinase complexes. Importantly, the levels of a different skp2 substrate, the Rb-related protein p130 (Tedesco et al. 2002), remained elevated in skp2/p27 double-knockout hepatocytes compared with skp2 knockout hepatocytes (Fig. $3 \mathrm{C}$ ), implying that loss of p27 does not unspecifically affect protein stability of other skp2 substrates. These observations allow an interpretation in line with earlier results (Spruck et al. 2001), showing that overexpression of p27 per se can lead to accumulation of cyclin E by secondarily stabilizing the protein.

\section{Loss of p27 turnover arrests the cell cycle before cyclin $A$ is expressed}

At this point of our analysis, we concluded that the accumulation of the cyclin kinase inhibitor p27 is responsible for the increase in cell size and DNA content observed in the skp2 knockout mouse. Furthermore, loss of p27 in the skp2/p27 double-knockout mouse reverted the proliferation defect in skp2 knockout hepatocytes from compensatory growth to cell division.

To address the question of how $\mathrm{p} 27$ interferes with cell cycle progression, we first measured p 27 levels after induction of liver regeneration in the different mouse strains. As wild-type hepatocytes entered the cell cycle, p27 levels dropped during early G1 (24 h post-PH) and remained low throughout the cell cycle (Fig. 4A). In accordance with our previous observation in fibroblasts, the levels of p27 remained unchanged in skp2 knockout 


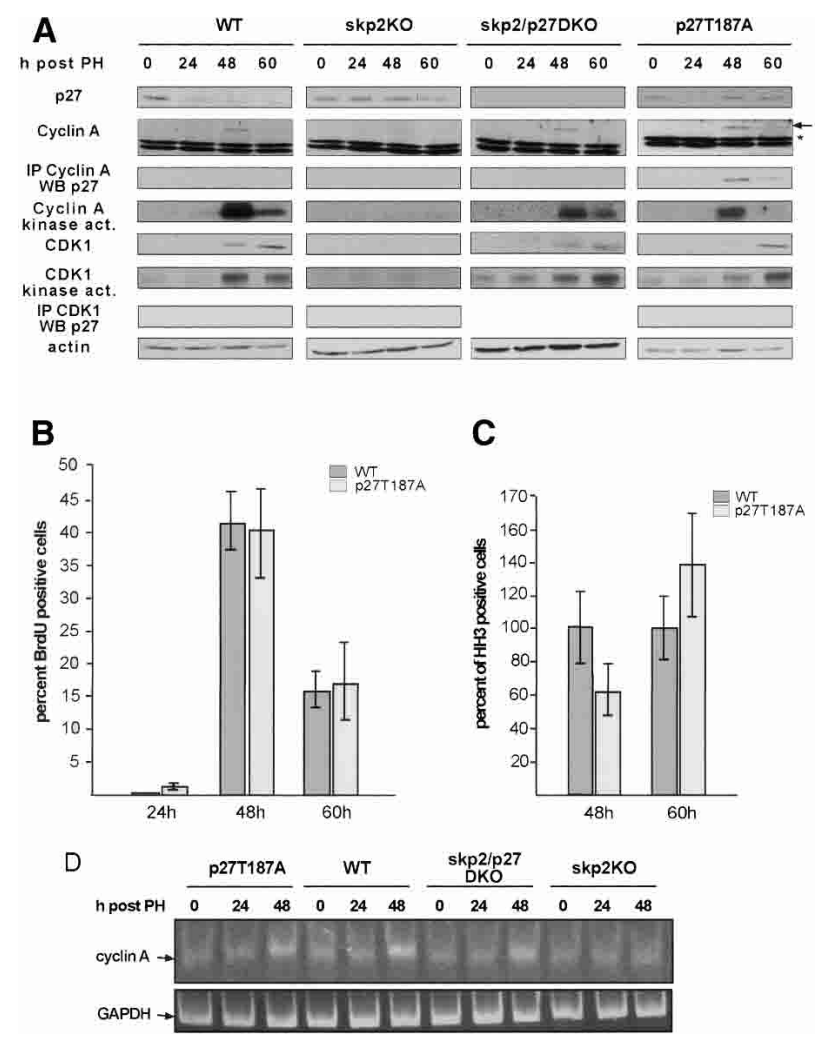

Figure 4. Degradation of p27 in early G1 is required for cell cycle progression. (A) Analysis of the expression levels of p27, cyclin A /* marks an unspecific band detected with the cyclin A antibody), cdk1, and actin; detection of cyclin A and cdk1-associated kinase activities; and determination of the amount of cyclin A and cdk1associated p27 in the indicated mouse strains after induction of liver regeneration. Analysis of BrdU uptake $(B)$ and mitosis as shown by HH3 labeling $(C)$ in wild-type and p27T187A mice. $(D)$ Semiquantitative RT-PCR of cyclin A cDNA using GAPDH as an internal control.

hepatocytes after $\mathrm{PH}$ (Fig. 4A), indicating an essential role for skp2 in the regulation of $\mathrm{p} 27$ expression when cells exit from quiescence (Malek et al. 2001). We then asked if the persistently high levels of p27 in the skp2 knockout hepatocytes in addition to inhibiting cdk2 kinase activity might also affect cyclin A-associated kinase activity, thereby preventing cell division. Wild-type and skp2/p27 double-knockout hepatocytes expressed cyclin $\mathrm{A}$ and its associated kinase activity at the onset of $\mathrm{S}$ phase at $48 \mathrm{~h}$ post- $\mathrm{PH}$ (Fig. 4A). In agreement with the role of cyclin $\mathrm{A}$ in promoting $\mathrm{S}$ phase and mitosis, skp2 knockout hepatocytes that incorporated BrdU at much reduced rates did not show any detectable cyclin A-associated kinase activity. This was not caused by increased binding of $\mathrm{p} 27$ to cyclin A/cdk complexes but by a complete absence of cyclin A protein in these cells (Fig. 4A). To test whether the failure to express cyclin A was caused by a lack of cyclin A transcription, we measured cyclin A RNA levels using a semiquantitative RT-PCR assay. As shown in Figure 4D, no increase over background levels of cyclin A RNA were detectable in skp2 knockout hepatocytes after induction of liver proliferation compared with skp2/p27 double-knockout and wild-type mice, which up-regulated cyclin A transcription at the onset of S phase. Therefore, the skp2 knockout hepatocytes must have been arrested at a point in G1 after the expression of cyclin E and prior to the expression of the cyclin A gene.

\section{Expression of p27 during the G2 phase does not interfere with liver cell proliferation}

A recent study by Nakayama et al. (2004) suggested that loss of skp2 leads to an inhibition of cdk1-associated kinase activity through binding of excess p27 to cyclin B/cdk1 complexes. This model was primarily derived from studies in skp2 knockout embryonic fibroblasts in which activation of cyclin A-associated kinase is not altered; however, passage through mitosis is inhibited by a proposed function of $\mathrm{p} 27$ as a cyclin B/cdk1 inhibitor. Our studies indicate that skp2 knockout hepatocytes are arrested in the cell cycle at a point before cyclin A is expressed and consequently should not express mitotic cdk1-associated kinase activity. To test the proposed function of p27 during the G2 phase of the cell cycle directly, we analyzed liver regeneration in p27T187A mice. This mouse expresses a mutant form of p27 that cannot be phosphorylated at T187. Our previous analysis of this mouse strain showed that p27 is degraded by at least two different proteolytic pathways, which act subsequently during the G1 phase. In the p27T187A knockin mouse, the first proteolytic mechanism functions but, due to the impaired second proteolytic mechanism turnover at the G1/S transition, is blocked, resulting in the accumulation of p27T187A to high levels during the remaining phases of the cell cycle (Malek et al. 2001). As shown in Figure 4A, p27T187A protein was down-regulated $24 \mathrm{~h}$ after $\mathrm{PH}$ as cells entered G1 from quiescence; however, due to the stabilization of p27T187A in late G1, reaccumulated to G0 levels as cells progressed into S, G2, and M phases. The reaccumulation of p27 in the p27T187A hepatocytes to levels comparable to the ones observed in skp2 knockout hepatocytes did not perturb the onset or duration of $\mathrm{S}$ phase after $\mathrm{PH}$ (Fig. 4B). We did, however, observe a $30 \%$ decrease in the number of $\mathrm{HH} 3$-positive cells at the $48 \mathrm{~h}$ and a $30 \%$ increase in the number of HH3-positive cells at the $60 \mathrm{~h}$ time points in the p27T187A strain (Fig. 4C). This delay in the passage through G2 was associated with a decrease in cyclin Aassociated kinase activity in the p27T187A mouse compared with wild-type mice because of increased binding of p27T187A to cyclin A (Fig. 4A). In contrast to skp2 knockout mice, no alterations in cyclin A transcription or cyclin A protein expression were detected in the p27T187A strain (Fig. 4A,D).

\section{The degradation of p27 during early G1 is essential for cell cycle progression}

To test the extent to which direct inhibition of cdk1associated kinase activity might contribute to the delayed detection of HH3-positive hepatocytes observed in p27T187A mice, we measured the levels of this kinase in the different mouse strains after induction of liver regeneration. In wild-type and skp2/p27 double-knockout hepatocytes, the cell cycle-regulated kinetics of cdk1 expression and cdkl-associated kinase activation were comparable (Fig. 4A). In agreement with our observation that skp2 knockout hepatocytes are arrested at a point before the expression of cyclin A, we did not detect any cdk 1 protein expression or cdk1-associated kinase activity in these cells. Due to the partial inhibition of cyclin 
A-associated kinase activity and the delay in cell cycle progression in the p27T187A strain, expression of cdk1 protein was delayed $12 \mathrm{~h}$. However, cdk1 kinase activity at the 60-h time point was comparable to wild-type activity at the 48 -h time point, indicating that the increased levels of p27 did not interfere with peak cdk1 kinase activity. Furthermore, in contrast to cyclin A, which was precipitated in a complex with p27 (Fig. 4A; Supplementary Fig. 1C), no p27, even though expressed at levels comparable to quiescent cells, was bound directly to cdk1 in p27T187A hepatocytes. Most importantly, the delayed activation of cdk1 in the p27T187A strain did not lead to an arrest in mitosis, and p27T187A hepatocytes do not display changes in ploidy or cell size (Figs. 1B, 2A,B).

Our study shows that the cellular changes observed in skp2 hepatocytes are rescued by simultaneous loss of the cyclin kinase inhibitor p27. This observation makes p27 the essential target of skp2-dependent protein turnover. Furthermore, by comparing liver regeneration in p27T187A and skp2 knockout mice, we find that the ability of p27 to arrest the cell cycle is limited to a short period in G1. This conclusion is based on the observation that p27T187A hepatocytes that degrade p27 after mitogenic stimulation, that is, within the first $24 \mathrm{~h}$ after induction of liver regeneration, will pass through the cell cycle, while skp2 knockout hepatocytes that fail to degrade p27 in early G1 are unable to undergo a mitotic division cycle. We believe that this decision is made in early G1 because reaccumulation of p27 during S, G2, and $M$ to levels comparable to quiescent cells does not interfere with cell division. The molecular consequences of p27 stabilization during early G1 or during S, G2, and $\mathrm{M}$ are also quite different. In skp2 knockout cells, p27 associates with cyclin E, which leads to an almost complete inhibition of cyclin E-associated kinase activity. As skp2 knockout hepatocytes cannot progress to a point in the cell cycle at which cyclin A is expressed, we conclude that the degradation of p27 in early G1 permits the expression of cyclin A probably by allowing activation of cyclin E-associated kinase activity. The proliferation defect in skp2 knockout hepatocytes is, therefore, a result of the inability of these cells to express cyclin A. In p27T187A hepatocytes, p27 associates primarily with cyclin A complexes, which leads to an only partial inhibition of its associated Histone $\mathrm{H} 1$ kinase activity. However, the reduced levels of cyclin A-associated kinase activity slow progression through the G2 phase, leading to a delayed activation of cdkl-associated kinase activity. This is, however, not due to a direct inhibition of cdk1 by 27 but solely to a delay in the expression of the cdk1 protein. Therefore, our data from hepatocytes do not support the role proposed by Nakayama et al. (2004) for p27 during the G2 phase of the cell cycle, namely, that of an inhibitor of cdk1 kinase activity. As tissuespecific differences might contribute to these divergent results, we would like to point out that our previous analysis of embryonic fibroblasts derived from $\mathrm{p} 27 \mathrm{~T} 187 \mathrm{~A}$ mice also did not point to a mitotic defect in these cells (Malek et al. 2001).

Based on the results presented in this work, we conclude that the mechanism that induces endoreduplication cycles in hepatocytes in response to excess levels of p27 must be operative during the G1 phase of the cell cycle. A feature of endoreduplicating cells is the lack of B-type kinase activity, which prevents progression through mitosis after the cell has completed $\mathrm{S}$ phase (Edgar and Orr-Weaver 2001). Due to the arrest of skp2 hepatocytes at a point before cdk1 is expressed, cdk1associated mitotic kinase activity is absent. An unsolved problem, however, is the question of how the low amount of cyclin E-associated cdk activity we find in skp2 knockout hepatocytes is able to induce DNA replication. From studies in cdk2 and cyclin E knockout mice (Geng et al. 2003; Ortega et al. 2003; Parisi et al. 2003), it is, however, known that cyclin $\mathrm{E}$ without measurable associated Histone H1 kinase activity is sufficient to allow endoreduplication, while loss of cyclin E1/E2 completely prevents endoreduplication in trophoblastic giant cells and megakaryocytes. Based on these observations, cyclin E could either act alone or associate with an as-yet-unknown kinase to induce replication when cdk2 is lost or inhibited.

In mouse and human livers, the number of polyploid cells increases with age or under conditions of cellular stress (Gupta 2000). It will be interesting to explore whether hepatocytes use cellular hypertrophy as a mechanism to maintain liver cell mass under conditions in which an increase in liver cell proliferation is not favorable, for instance, chronic liver damage or liver cirrhosis, conditions known to lead to liver cell carcinomas.

\section{Materials and methods}

Animals and partial hepatectomy procedure

129/Sv p27 heterozygous knockout mice (Fero et al. 1996) were crossed with heterozygous C57/B6J skp2 knockout mice (Nakayama et al. 2000) to generate skp2/p27 double-knockout animals. All genotyping was done as described (Fero et al. 1996; Nakayama et al. 2000). In all experiments 8-10-week-old wild-type and mutant littermates or cousins from two different litters were used. Mice were killed at the indicated time points after surgery, and the number of mice analyzed ranged from 2 to 6 per time point. Partial hepatectomies were performed as described (Satyanarayana et al. 2003).

BrdU, $\beta$-catenin, and HH3 staining

BrdU staining of 6- $\mu \mathrm{m}$ cryostat sections was done as described (Satyanarayana et al. 2003). The BrdU-labeling index was determined by counting the number of BrdU-positive cells in 20 low-power $(10 \times)$ magnification fields chosen at random and expressing the number of BrdU-labeled nuclei as a percentage of all nuclei counted. At least three sections and three visual fields of each collected liver sample were quantified.

$\beta$-Catenin (BD Transduction Laboratories) staining was performed on paraffin sections after boiling the sections in Tris-EDTA ( $\mathrm{pH} 9.0$ ) for 20 min. After blocking the slides with $1 \%$ BSA/PBS for $1 \mathrm{~h}$, the antibody was incubated for $2 \mathrm{~h}$ in PBS $/ 0.05 \%$ BSA.

Nuclei positive for Histone $\mathrm{H} 3$ phosphorylation were detected using an anti-HH3 antibody (Cell Signalling), and analysis was performed as described (Brenner et al. 2003).

Feulgen staining

To determine DNA content, 3-um-thick sections were Feulgen-stained using the Feulgen Staining Kit (Merck). Ploidy analysis was performed with the Ahrens ICM, Cytometrie System. Statistical analysis was done using the Dunnet-T Test (DNA ploidy) and the mixed models analysis of variance (nuclear size analysis).

Semiquantitative RT-PCR

RNA extraction was done as described (Satyanarayana et al. 2003). For cDNA synthesis, $2 \mu \mathrm{g}$ of RNA was used. The RT reactions were carried out using SuperScript-II RNase H Reverse Transcriptase (Invitrogen). For semiquantitative RT-PCR, $1 \mu \mathrm{L}$ of cDNA was amplified using the following cycle profile: denaturation at $94^{\circ} \mathrm{C}$ for $30 \mathrm{sec}$, annealing at $57^{\circ} \mathrm{C}$ for $30 \mathrm{sec}$, and extension at $72^{\circ} \mathrm{C}$ for $45 \mathrm{sec}$ using Platinum Taq Poly- 
merase (Invitrogen), for 30 cycles. GAPDH was used as a control. Primer sequences were as follows: Cyclin A: forward, 5'-TCGACGGGTTGCTC CTCTTAA-3', backward, 5'-CTGCTGGTCCTTCATGGAAAG-3'; Cyclin E: forward, 5'-TGATGAAGGCCCTTAAGTGG-3', backward, 5'GGCCACTTGGACATAGACAT-3'; GAPDH: forward, 5'-TCAAGAAG GTGGTGAAGCAGGC-3', backward, 5'-GGTCCACCACCCTGTTGC TGTA-3'. All PCR products were subcloned into the pCR II-TOPO vector (Invitrogen) and sequenced to confirm the amplification of the target genes.

Western blots, immunoprecipitations, and kinase assays The antibodies used in these experiments were mouse monoclonal antip27 (BD Transduction Laboratories), rabbit polyclonal anti-cyclin A (Santa Cruz), anti-actin (ICN), anti-Cdk2 (Santa Cruz), anti-cyclin D1 (DCS6, Labvision), anti-CDK1 (Ab-4, Labvision), anti-p130 (C20, Santa Cruz), anti-cyclin E ("Ab-1," Labvision), or rabbit anti-cyclin E "Ab-2" (Clurman et al. 1996). Western blots, kinase assays, and immunoprecipitations were essentially done as described (Malek et al. 2001).

\section{Acknowledgments}

We thank Holly Sundberg Malek and Achim Gossler for helpful discussions and critically reading the manuscript. We are also grateful to Keiko and Keiichi Nakayama for sharing the skp2 knockout mouse. This work was supported by grants from the Deutsche Forschungsgemeinschaft DFG MA 2090/2-1 and the Max Eder Programm of the Deutsche Krebshilfe to N.P.M.

\section{References}

Bornstein, G., Bloom, J., Sitry-Shevah, D., Nakayama, K., Pagano, M., and Hershko, A. 2003. Role of the SCFSkp2 ubiquitin ligase in the degradation of p21Cipl in S phase. J. Biol. Chem. 278: 25752-25757.

Brenner, R.M., Slayden, O.D., Rodgers, W.H., Critchley, H.O., Carroll, R., Nie, X.J., and Mah, K. 2003. Immunocytochemical assessment of mitotic activity with an antibody to phosphorylated histone $\mathrm{H} 3$ in the macaque and human endometrium. Hum. Reprod. 18: $1185-1193$

Carrano, A.C., Eytan, E., Hershko, A., and Pagano, M. 1999. SKP2 is required for ubiquitin-mediated degradation of the $\mathrm{CDK}$ inhibitor p27. Nat. Cell Biol. 1: 193-199.

Clurman, B.E., Sheaff, R.J., Thress, K., Groudine, M., and Roberts, J.M. 1996. Turnover of cyclin $\mathrm{E}$ by the ubiquitin-proteasome pathway is regulated by cdk2 binding and cyclin phosphorylation. Genes \& Dev. 10: 1979-1990.

Coats, S., Flanagan, W.M., Nourse, J., and Roberts, J.M. 1996. Requirement of p27Kipl for restriction point control of the fibroblast cell cycle. Science 272: 877-880.

Edgar, B.A. and Orr-Weaver, T.L. 2001. Endoreplication cell cycles: More for less. Cell 105: 297-306.

Fero, M.L., Rivkin, M., Tasch, M., Porter, P., Carow, C.E., Firpo, E., Polyak, K., Tsai, L.H., Broudy, V., Perlmutter, R.M., et al. 1996. A syndrome of multiorgan hyperplasia with features of gigantism, tumorigenesis, and female sterility in p27(Kip1)-deficient mice. Cell 85: 733-744.

Geng, Y., Whoriskey, W., Park, M.Y., Bronson, R.T., Medema, R.H., Li, T., Weinberg, R.A., and Sicinski, P. 1999. Rescue of cyclin D1 deficiency by knockin cyclin E. Cell 97: 767-777.

Geng, Y., Yu, Q., Sicinska, E., Das, M., Schneider, J.E., Bhattacharya, S., Rideout, W.M., Bronson, R.T., Gardner, H., and Sicinski, P. 2003. Cyclin E ablation in the mouse. Cell 114: 431-443.

Guidotti, J.E., Bregerie, O., Robert, A., Debey, P., Brechot, C., and Desdouets, C. 2003. Liver cell polyploidization: a pivotal role for binuclear hepatocytes. J. Biol. Chem. 278: 19095-19101.

Gupta, S. 2000. Hepatic polyploidy and liver growth control. Semin. Cancer Biol. 10: 161-171.

Kamura, T., Hara, T., Kotoshiba, S., Yada, M., Ishida, N., Imaki, H., Hatakeyama, S., Nakayama, K., and Nakayama, K.I. 2003. Degradation of p57Kip2 mediated by SCFSkp2-dependent ubiquitylation. Proc. Nat1. Acad. Sci. 100: 10231-10236.
Kim, S.Y., Herbst, A., Tworkowski, K.A., Salghetti, S.E., and Tansey, W.P. 2003. Skp2 regulates Myc protein stability and activity. Mol. Cell 11: 1177-1188.

Kiyokawa, H., Kineman, R.D., Manova-Todorova, K.O., Soares, V.C., Hoffman, E.S., Ono, M., Khanam, D., Hayday, A.C., Frohman, L.A., and Koff, A. 1996. Enhanced growth of mice lacking the cyclin-dependent kinase inhibitor function of p27(Kip1). Cell 85: 721-732.

Li, X., Zhao, Q., Liao, R., Sun, P., and Wu, X. 2003. The SCF(Skp2) ubiquitin ligase complex interacts with the human replication licensing factor Cdt1 and regulates Cdt1 degradation. J. Biol. Chem. 278: 30854-30858.

Malek, N.P., Sundberg, H., McGrew, S., Nakayama, K., Kyriakidis, T.R., and Roberts, J.M. 2001. A mouse knock-in model exposes sequential proteolytic pathways that regulate p27Kip1 in G1 and S phase. $\mathrm{Na}$ ture 413: 323-327.

Mendez, J., Zou-Yang, X.H., Kim, S.Y., Hidaka, M., Tansey, W.P., and Stillman, B. 2002. Human origin recognition complex large subunit is degraded by ubiquitin-mediated proteolysis after initiation of DNA replication. Mol. Cell 9: 481-491.

Minamishima, Y.A. and Nakayama, K. 2002. Recovery of liver mass without proliferation of hepatocytes after partial hepatectomy in Skp2-deficient mice. Cancer Res. 62: 995-999.

Montagnoli, A., Fiore, F., Eytan, E., Carrano, A.C., Draetta, G.F., Hershko, A., and Pagano, M. 1999. Ubiquitination of p27 is regulated by Cdk-dependent phosphorylation and trimeric complex formation. Genes \& Dev. 13: 1181-1189.

Nakayama, K., Ishida, N., Shirane, M., Inomata, A., Inoue, T., Shishido, N., Horii, I., and Loh, D.Y. 1996. Mice lacking p27(Kip1) display increased body size, multiple organ hyperplasia, retinal dysplasia, and pituitary tumors. Cell 85: 707-720.

Nakayama, K., Nagahama, H., Minamishima, Y.A., Matsumoto, M., Nakamichi, I., Kitagawa, K., Shirane, M., Tsunematsu, R., Tsukiyama, T., Ishida, N., et al. 2000. Targeted disruption of Skp2 results in accumulation of cyclin E and p27(Kip1), polyploidy and centrosome overduplication. EMBO J. 19: 2069-2081.

Nakayama, K., Nagahama, H., Minamishima, Y.A., Miyake, S., Ishida, N., Hatakeyama, S., Kitagawa, M., Iemura, S., Natsume, T., and Nakayama, K.I. 2004. Skp2-mediated degradation of p27 regulates progression into mitosis. Dev. Cell 6: 661-672.

Ohtani, K., DeGregori, J., and Nevins, J.R. 1995. Regulation of the cyclin E gene by transcription factor E2F1. Proc. Nat1. Acad. Sci. 92: 1214612150.

Ortega, S., Prieto, I., Odajima, J., Martin, A., Dubus, P., Sotillo, R., Barbero, J.L., Malumbres, M., and Barbacid, M. 2003. Cyclin-dependent kinase 2 is essential for meiosis but not for mitotic cell division in mice. Nat. Genet. 35: 25-31.

Parisi, T., Beck, A.R., Rougier, N., McNeil, T., Lucian, L., Werb, Z., and Amati, B. 2003. Cyclins E1 and E2 are required for endoreplication in placental trophoblast giant cells. EMBO J. 22: 4794-4803.

Satyanarayana, A., Wiemann, S.U., Buer, J., Lauber, J., Dittmar, K.E. Wustefeld, T., Blasco, M.A., Manns, M.P., and Rudolph, K.L. 2003. Telomere shortening impairs organ regeneration by inhibiting cell cycle re-entry of a subpopulation of cells. EMBO J. 22: 4003-4013.

Sheaff, R.J., Groudine, M., Gordon, M., Roberts, J.M., and Clurman, B.E. 1997. Cyclin E-CDK2 is a regulator of p27Kip1. Genes \& Dev. 11: 1464-1478.

Spruck, C., Strohmaier, H., Watson, M., Smith, A.P., Ryan, A., Krek, T.W., and Reed, S.I. 2001. A CDK-independent function of mammalian Cks1: Targeting of SCF(Skp2) to the CDK inhibitor p27Kip1. Mol. Cell 7: 639-650.

Sutterluty, H., Chatelain, E., Marti, A., Wirbelauer, C., Senften, M., Muller, U., and Krek, W. 1999. p45SKP2 promotes p27Kip1 degradation and induces S phase in quiescent cells. Nat. Cell Biol. 1: 207214.

Tedesco, D., Lukas, J., and Reed, S.I. 2002. The pRb-related protein p130 is regulated by phosphorylation-dependent proteolysis via the protein-ubiquitin ligase SCF(Skp2). Genes \& Dev. 16: 2946-2957.

von der Lehr, N., Johansson, S., Wu, S., Bahram, F., Castell, A., Cetinkaya, C., Hydbring, P., Weidung, I., Nakayama, K., Nakayama, K.I., et al. 2003. The F-box protein Skp2 participates in c-Myc proteosomal degradation and acts as a cofactor for c-Myc-regulated transcription. Mol. Cell 11: 1189-1200. 


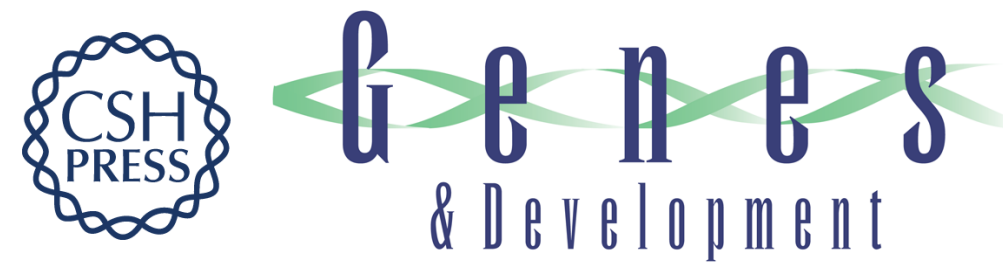

\section{Skp2-dependent degradation of p27kip1 is essential for cell cycle progression}

Uta Kossatz, Nils Dietrich, Lars Zender, et al.

Genes Dev. 2004, 18:

Access the most recent version at doi:10.1101/gad.321004

Supplemental http://genesdev.cshlp.org/content/suppl/2004/10/07/18.21.2602.DC1
Material

References This article cites 31 articles, 14 of which can be accessed free at: http://genesdev.cshlp.org/content/18/21/2602.full.html\#ref-list-1

License

Email Alerting

Receive free email alerts when new articles cite this article - sign up in the box at the top Service right corner of the article or click here.

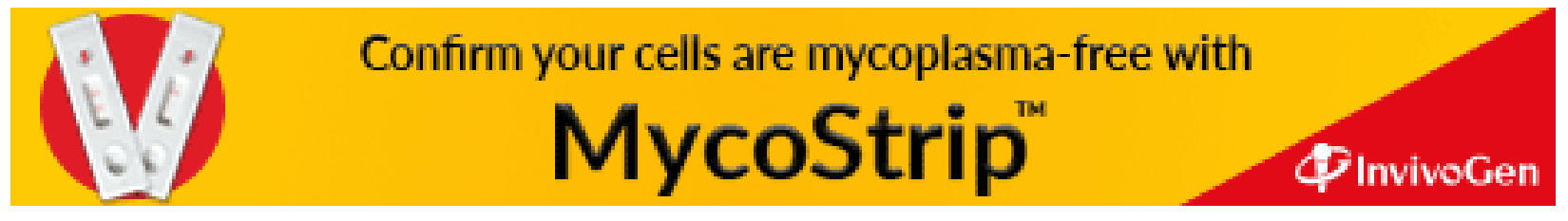

